\title{
AUTOCHTHONOUS CYSTIC ECHINOCOCCOSIS IN PATIENTS WHO GREW UP IN GERMANY
}

\author{
J Richter (Joachim.Richter@med.uni-duesseldorf.de) ${ }^{1}$, A Orhun ${ }^{1}$, B Grüner ${ }^{2}$, I Müller-Stöver ${ }^{1}$, S Reuter ${ }^{1}$, T Romig 3 , D \\ Häussinger ${ }^{1}$, P Kern $^{2}$ \\ 1. Tropical Medicine Unit, University Hospital for Gastroenterology, Hepatology and Infectious Diseases, Heinrich-Heine- \\ University, Düsseldorf, Germany \\ 2. Comprehensive Infectious Diseases Center (CIDC), Division of Infectious Diseases and Clinical Immunology, University \\ Hospital of Ulm, Germany \\ 3. Department of Parasitology, University Hohenheim, Stuttgart, Germany
}

Human cystic echinococcosis (CE) is a widespread zoonosis. Cases occurring in Germany are considered to result from imported infection and it is unclear if Echinococcus granulosus (sensu lato) is still transmitted in Germany. Therefore, exposure was investigated in 15 patients with cystic echinococcosis ( 7 female, 8 male; agerange 16-68, with a median of 48 years) who grew up in Germany. Fourteen patients had most likely acquired their infection in rural Germany, 11 from local dogs, one from an imported dog, two without obvious dog contacts. Taking into account multiple conceivable confounding factors might also account for some of infections: contacts with imported dogs or contact with dogs during travel in highly endemic regions, and ingestion of food contaminated by worm ova, whether in Germany or abroad. However, in at least two cases autochthonous transmission is beyond doubt, because these patients had never left Germany. The long pre-symptomatic development of cystic echinococcosis does not allow for a precise evaluation of the actual epidemiological situation. Compulsory notification of human cystic echinococcosis is an important instrument in the surveillance of the disease in humans. Regular inquiries at laboratories carrying out work in the field of veterinary medicine and at slaughterhouses, supervision of dogs at risk as well as genetic investigations on the strain or species of the causal agent of cystic echinococcosis are needed.

\section{Introduction}

Echinococcosis is a zoonosis occurring worldwide. Two forms of echinococcosis can affect humans: alveolar and cystic echinococcosis. The causal agent of alveolar echinococcosis is Echinococcus multilocularis. It is found in foxes, dogs, cats and wolves. The main host, the fox, contracts $E$. multilocularis mostly from eating rodents. E. multilocularis is known to sporadically transmit to humans in Germany [1, 2]. The domestic dog is the most frequent main host for $E$. granulosus and life cycles occur between dogs and different domestic animals including sheep or pigs. Worldwide human cystic echinococcosis following infection with several forms of the heterogeneous $E$. granulosus complex, accounts for most cases of human echinococcosis. The worldwide incidence of cystic echinococcosis is estimated to amount to 100,000 to 300,000 cases annually [3, 4]. Pastoral populations in East Africa, Kazakhstan, Kyrgizstan, northwest-China and
Tibet are particularly at risk. In Europe, human infections occur predominantly in the south and east $[3,4]$.

In Germany cystic echinococcosis was known to be transmitted autochthonously until the sixties. Nowadays, however, cystic echinococcosis is perceived as an infection of migrants acquired in their countries of origin. Established transmission cycles are considered to have been interrupted in Germany by the improvement of hygiene in slaughterhouses, preventing the access of dogs to infected organs of slaughtered animals. Sporadically, cystic echinococcosis is registered in German individuals, but the high mobility of the population and the long-lasting pre-symptomatic phase precludes the possibility of reconstructing where the infection had been acquired.

At present, it is not clear, whether or not transmission of cystic echinococcosis to humans still occurs in Germany. Since 2001, cases of cystic echinococcosis are a mandatorily notifiable disease that needs to be reported to the Robert Koch-Institut (RKI, German national public health institute). Between 2001 and 2007 some 413 of notified cases were identified as new infections. Notifying doctors communicated the most probable source of infection in 296 of these 413 cases. Among these 296 cases more than one sixth ( 56 cases) of infections were deemed as having been acquired in Germany [5]. Therefore, we attempted to identify particular risks and the most probable source of infection by conducting a survey among patients with cystic echinococcosis who grew up in Germany.

\section{Patients, materials and methods}

Patients were recruited among individuals diagnosed with cystic echinococcosis, who grew up in Germany, and attended our regional referral centers in Germany, between 1999 and 2008. Patients were given detailed information on the study and asked for their consent to participate. Criteria for the definite diagnosis of cystic echinococcosis were imaging findings (ultrasound, computerized tomography and magnetic resonance imaging) showing a typical morphology for cystic echinococcosis. The findings were, classified according to the recommendations of the World Health Organization (WHO) - Informal Working Group on Echinococcosis [6]. Patients with transitional partially solidified cysts (WHO-CE 
4) are sometimes difficult to diagnose on imaging findings alone: these cases were only included when other parameters (histology, detection of hooks or protoscolices in cystic fluid, antibodies to E. granulosus) supported or confirmed the imaging findings [7-9] (Table). Treatment and follow up were performed according to the stage of the disease $[3,7,9]$.

Patients were asked to answer a detailed questionnaire concerning their entire life history and living conditions in all places where they had lived, with emphasis on urban or rural environment, dog contacts, whether they knew if slaughtering was controlled or not in the area they lived, and possibilities of an accidental transportation of parasite ova from dog faeces to raw food by cockroaches or flies. Patients were asked to present a detailed life-long travel history answering the same questions as in the questionnaire above. Where patients reported contacts to dogs, information on the origin and history of displacements of the dogs was also obtained.

\section{Results}

\section{History of exposure}

Twentytwo patients with cystic echinococcosis, who had grown up in Germany, were recruited for the survey. Seven of them were excluded because their data were incomplete. The 15 remaining German cystic echinococcosis patients, seven female, eight male, were able to give exhaustive information to answer the questionnaire. Their age at the date of diagnosis was 16 to 68 years (median 48 years). Detailed results on their history of travel and exposure to dogs and findings (laboratory and imaging) are shown in the Table. Since patients were uncertain about possible transmission risks, other than the two mentioned above, the cumulative duration of dog contacts in and outside Germany was defined as the best measurable risk factor.

Only two patients ( $n^{\circ} 4$ and $n^{\circ} 6$ ) did not recall contacts with dogs. These two patients mainly had lived in Germany, although one patient $\left(n^{\circ} 4\right)$ had stayed for some months in a high risk area, Northern Africa, the other patient $\left(n^{\circ} 6\right)$ had travelled in areas with a high incidence of cystic echinococcosis only on holidays.

Among the patients who recalled having been in contact with dogs, one patient $\left(n^{\circ} 9\right)$ reported an extended stay in a rural area of central Italy, where he had kept dogs. For many years he also owned dogs in Germany.

Two patients ( $n^{\circ} 13$ and $n^{\circ} 14$ ) had never left Germany even for short periods. For 10 patients the cumulative time of exposure to dogs was longest in Germany. One of them, patient $n^{\circ} 11$, had imported his dog from Hungary to Germany, whereas the others had been exposed to local dogs only. Some of the latter patients may have also occasionally been exposed to cystic echinococcosis outside Germany, such as patient $n^{\circ} 8$, a medical doctor, who had worked in Brazil for four years. However, he had lived in an area of very low endemicity and he did not recall any contact with local dogs there $[4 ; 10]$. Although patient $n^{\circ} 7$ had lived for some time in highly endemic regions he did not remember any contact with dogs during these stays. Five of the patients reported only short holidays in endemic countries but did not remember any contact with local dogs $\left(n^{\circ} 2, n^{\circ} 5, n^{\circ} 10, n^{\circ} 12, n^{\circ} 15\right)$. Patient $n^{\circ} 3$ had taken her pet dog with her on holidays to Italy (Riccione, Emilia- Romagna).

\section{Discussion}

Unexpectedly, in the majority of cases included in our study, infection by a local dog was the most likely explanation of cystic echinococcosis in patients who grew up in Germany. In two of the 15 cases there is no doubt about autochthonous infection, because they have never in their life-time travelled outside Germany. Our hypothesis of autochtonous infection in Germany may be confuted in some other cases where infection might also be interpreted as a travel associated disease [11].

The probability of autochthonous transmission depends on the prevalence of cystic echinococcosis in domestic animals, on the access of dogs to raw slaughter offal or to infected animal carcasses and the intensity and duration of contact between dogs and humans. Dog ownership, in particular the duration of dog ownership is the best established risk factor for human cystic echinococcosis [12]. Sometimes, humans may become infected without contact to dogs; indirect transmission occurs, when arthropods such as flies or cockroaches or birds transport ova of $E$. granulosus from dog excrements on raw food, e.g. salad [12-18]. In a rural environment, small children may also become infected when they accidentally ingest ova after crawling on the floor which has been contaminated by excrements of an infected dog. The type of water supply (i.e. tap water, wells) has also been suggested to be associated with the risk of human cystic echinococcosis. In a highly endemic rural area of Kazakhstan five out of 120 selected soil samples contained eggs of E. granulosus [19]. Obviously, no patient in our series could exclude these conceivable indirect ways of transmission. Indirect transmission most likely accounts for those two of our patients who did not recall any dog contact and may account for some other case, although an occasional dog contact which has been forgotten cannot be ruled out completely. However, the risk of indirect transmission by such sporadic events appears to be much lower than a long-lasting contact to a dog that is harbouring adult worms and thus constantly excreting worm ova over a time period of up to 22 months [10, 12-18].

Unfortunately, in Germany reliable data on the actual prevalence of cystic echinococcosis in domestic animals are not available. Infections of cattle were sporadically reported in Germany until the nineties $[10 ; 20]$. The prevalence of $E$. granulosus infections in dogs is assumed to be very low. The only vertical analysis available revealed $43 \mathrm{E}$. multilocularis cases but no $\mathrm{E}$. granulosus confirmed by molecular analysis out of more than 21,000 specimens of dog excrements sent by Veterinary Medical Clinics to a German Veterinary Medicine laboratory in 2004 and 2005 [21]. This observation, however, cannot be taken as representative, because it can be assumed that rural free raging dogs are grossly underrepresented in this sample.

Controlled slaughtering and inspection of meat, as well as routine deworming of dogs have contributed to an almost complete disappearance of $E$. granulosis in Germany and many neighbouring countries. However, active foci are still present in countries close to Germany and frequently visited by Germans such as Poland and the Mediterranean countries [10; 20; 22].

A persistence of a reservoir of cystic echinococcosis in Germany cannot be excluded and new risks may arise, such as importation of infected dogs from endemic areas without deworming as well as the illegal slaughtering of domestic animals. Recently the reintroduction of cystic echinococcosis to slaughterhouses of a non- 
endemic country has been observed in the Netherlands, where infected cattle had been imported from Romania [23].

As a possibility to more reliably identify the sources of human cystic echinococcosis in Germany, genetic investigations of the parasite could be helpful. In former times, cystic echinococcosis of domestic animals in Germany most frequently occurred in cattle. It can therefore be assumed that cystic echinococcosis in Germany was due to the genetically distinct cattle strain (G5 or E. ortleppi). An old persisting endemicity would be due to this agent. Genotypic analysis could indicate the origin of the infectious agent: sheepand buffalo strains (G1/G3) are endemic in the Mediterranean region, and the pig strain (G7 or $E$. canadensis) is endemic in eastern Europe [9; D’Amelio, personal communication, 2007].

The actual risk of transmission is very difficult to determine because of the very slow development and persistence of cysts in patients for years or even decades. Considering the size and morphology of the cysts in our patients, infection must have taken place many years before diagnosis. The two older patients, who had never travelled outside Germany and who had inactive cysts, might have been infected in a period before cystic echinococcosis control had been completely achieved in Germany. This view may be supported by observations from other countries where cystic echinococcosis had been eradicated in animals but cysts were found in humans for many years after transmission had been interrupted $[24,25]$. To fully exclude sporadic infection acquired in endemic regions in the younger patients is impossible. Nowadays, it is difficult to find young Germans who have never travelled abroad and infections which are transmitted at present will most probably be discovered in humans only after years or even decades.

Furthermore, false negative serology results occur frequently, especially in young cysts (WHO-CL, WHO-CE1) and inactive cysts (WHO-CE5) [3, 6-10, 13, 17, 26, 27]. Obviously, laboratory notifications miss those cases where specific antibodies are not yet detectable. An inquiry among German pathologists showed a number of approximately 70 new cases of cystic echinococcosis detected each year, between 1995 and 2001 [28]. In our series, histopathology had been performed in less than half of the cases. Moreover, some cases of cystic echinococcosis in German patients may be misclassified as alveolar echinococcosis, because the notion that alveolar echinococcosis is endemic in Germany is common, whereas cystic echinococcosis is considered a disease of migrants. Reporting clinicians may also overestimate risks of acquiring cystic echinococcosis abroad because they believe that it cannot be transmitted in Germany. Thereby, cystic echinococcosis cases estimated of having been acquired in Germany are likely to be underreported. Furthermore, differential diagnosis between congenital cysts and cystic echinococcosisis is sometimes difficult [29]. Finally, many medical doctors in Germany are not yet sufficiently familiar with the notification procedures and these have not found their place in medical routine. Therefore, the real number of cystic echinococcosiscases is likely to exceed the number of notified cases. This notion is supported by a recent study on alveolar echniococcosis where a threefold higher incidence was found compared with the national surveillance figures [30].

The main limitations of our study are the impossibility to retrospectively assess transmission risks besides dog contacts and the high mobility of Germans with frequent stays and holidays in endemic areas. Nevertheless, despite of these difficulties, it must be acknowledged that autochthonous transmission of cystic echinococcosis in our patient series had occurred without doubt at least in two of 15 cases investigated and that the cumulative duration of dog contacts in the majority of the remaining patients was highest within Germany.

At present it is not possible to assess the actual risk of cystic echinococcosis transmission in Germany. The difficulties arise from: the very long delay between infection and diagnosis; the permanence of (apparently) inactive cysts which do not cause symptoms for years or even decades, insufficient data on the frequency of cysts found in slaughtered animals including the possible practice of uncontrolled slaughtering, and insufficient data on the incidence of E. granulosus infection in local dogs.

\section{Conclusions}

Cystic echinococcosis is a worldwide zoonosis, which occurs sporadically also in Germany. The results of our study strongly support the notion that a significant proportion of the sporadic infections are due to autochthonous transmission in Germany, although cystic echinococcosis may also be acquired from dogs imported from a region of high endemicity or during a stay in a highly endemic region. The retrospective design of our study does not permit an estimation of the actual risk of transmission of cystic echinococcosis in Germany. However, new threats have to be taken into account. The European Union is expanding and animal imports are likely to increase especially from highly endemic countries in Europe. Epidemiological figures on the actual transmission are difficult to obtain. Therefore, compulsory notification of human cystic echinococcosis is one instrument for surveillance that has to be maintained. Regular inquiries in veterinary medicine laboratories and slaughterhouses, investigation of dogs at risk of infection as well as genetic investigations on the strain or species of the causal agent of cystic echinococcosis are also justified.

\section{Acknowledgements}

We thank the patients for their enthusiastic support. The Paul-EhrlichSociety of Chemotherapy supported the establishment of the German Echinococosis Registry in Ulm, Germany. This work is part of medical theses by A Orhun and B Just.

\section{References}

1. Kern P, Bardonnet K, Renner E, Auer H, Pawlowski Z, Ammann RW et al. European Echinococcosis Registry. European echinococcosis registry: human alveolar echinococcosis, Europe, 1982-2000. Emerg Infect Dis. 2003;9(3):343-9.

2. Schweiger A, Ammann RW, Candinas D, Clavien PA, Eckert J, Gottstein B et al. Human alveolar echinococcosis after fox population increase, Switzerland. Emerg Infect Dis. 2007;3(6):878-82.

3. Kern P, Reuter S, Kratzer W, Buttenschoen K. Treatment of cystic echinococcosis. Dtsch Med Wochenschr. 2001;19;126(3):51-4.

4. Romig T, Epidemiology of echinococcosis, Langenbecks Arch Surg. 2003;388: 209-17

5. Robert Koch-Institut. Infektionsepidemiologisches Jahrbuch meldepflichtiger Krankheiten 2001-2007. (yearbooks of epidemiology of infections in Germany). Available from: http://www.rki.de/cln_100/nn_196322/DE/Content/Infekt/ Jahrbuch/jahrbuch_node.html?_nnn=true

6. World Health Organization (WHO). Puncture Aspiration Injection and Reaspiration - an option for the treatment of cystic echinococcosis. WHO Informal Working Group on Echinococcosis (WHO-IWGE) 2001; WHO/CDS/CSR/ APH/2001. Available from: http://whqlibdoc.who.int/hq/2001/WHO_CDS_CSR_ APH_2001.6.pdf

7. Junghanss T, da Silva AM, Horton J, Chiodini PL, Brunetti E. Clinical management of cystic echinococcosis: state of the art, problems, and perspectives. Am J Trop Med Hyg. 2008;79(3):301-11. 
8. Wellinghausen N, Kern P. A new ImmunoCAP assay for detection of Echinococcus multilocularis-specific IgE. Acta Trop. 2001; 79(2): 123-7.

9. Kern P. Echinococcus granulosus infection: clinical presentation, medical treatment and outcome. Langenbecks Arch Surg. 2003;388(6): 413-20.

10. Eckert J, Schantz PM, Gasser RB, Torgerson PR, Bessonov AS, Movsesian SO, et al. Geographic distribution and prevalence. In: Eckert J, Gemmell MA, Meslin FX, Pawlowski ZS (eds.): WHO/OIE manual on echinococcosis in humans and animals: a public health problem of global concern. World Organization for Animal Health 2001, Paris, pp. 100-142, 265. Available from: http://whqlibdoc. who.int/publications/2001/929044522X.pdf

11. Brunetti E, Gulizia R, Garlaschelli AL, Filice C. Cystic echinococcosis of the liver associated with repeated international travels to endemic areas. J Travel Med. 2005; 12(4):225-8.

12. Larrieu EJ, Costa MT, del Caprio M, Moguillansky S, Bianchi G, Yadon ZE. A case-control study of the risk factors for cystic echinococcosis among the children of Rio Negro province, Argentina. Ann Trop Med Parasitol. 2002;96(1): 43-52.

13. Brunetti E, Filice C, Genchi, C. Genere Echinococcus in: de Carneri I edt. Parassitologia generale e umana. Casa Editrice Ambrosiana 13th edition, 2004 Milan Italy. pp.:317 - 329.

14. Torgerson PR, Karaeva RR, Corkeri N, Abdyjaparov TA, Kuttubaev OT, Shaikenov RS. Human cystic echinococcosis in Kyrgystan: an epidemiological study. Acta Trop. 2003;85(1): 51-61

15. Dowling PM, Abo-Shehada MN, Torgerson PR. Risk factors associated with human cystic echinococcosis in Jordan: results of a case-control study. Ann Trop Med Parasitol. 2000;94(1):69-75.

16. Dowling PM, Torgerson PR. A cross-sectional survey to analyse the risk factors associated with human cystic echinococcosis in an endemic area of midWales. Ann Trop Med Parasitol. 2000;(3)94:241-5.

17. Carmona C, Perdomo R, Carbo A, Alvarez C, Monti J, Grauert R et al. Risk factors associated with human cystic echinococcosis in Florida, Uruguay: results of a mass screening study using ultrasound and serology. Am J Trop Med Hyg. 1998;58(5):599-605

18. Wang $Q$, Qiu JM, Schantz P, He JG, Ito A, Liu FJ. Investigation of risk factors for development of human hydatidosis among household raising livestock in Tibetan areas of Western Sichuan province. Zhongguo Ji Sheng Chong Wue Yu Ji Sheng Chong Bing Za Zhi 2001;19(2): 93-6.

19. Shaikenov BS, Rysmukhambetova AT, Massenov B, Deplazes P, Mathis A, Torgerson PR. Short report: the use of a polymerase chain reaction to detect Echinococcus granulosus (G1 strain) eggs in soil samples. Am J Trop Med Hyg. 2004;71(4):441-3.

20. Romig T, Dinkel A, Mackenstedt U. The present situation of echinococcosis in Europe. Parasitology Int. 2006;55 Suppl:S187 - 191.

21. Dyachenko V, Pantchev N, Gawlowska S, Vrhovec MG, Bauer C. Echinococcus multilocularis infections in domestic dogs and cats from Germany and other European countries. Vet Parasitol. 2008;157(3-4):244-253.

22. Montinaro L, Sisinni AG, Sartorelli P. L'echinococcosi: un'endemia persistente. G Ital Med Lav Ergon. 2004;26(3):202-7.

23. Aalten M, Züchner L, Bruinier E, Holzhauer M, Wouda W, Bergsteede $F$ et al.. Reintroduction of E. granulosus by import of cows in the Netherlands. Tijdschr Diergeneeskd. 2008;133(21): 898-902.

24. Beard T.C. The elimination of echinococcosis from Iceland. Bull World Health Organ. 1973;48(6):653-60.

25. Koea JB. Cystic lesions of the liver: 6 years of surgical management in New Zealand. N Z Medical J. 2008;121(1277): 61-9.

26. Gavidia CM, Gonzalez AE, Zhang W, McManus DP, Lopera L, Ninaquispe B, et al Diagnosis of cystic echinococcosis, central Peruvian highlands. Emerg. Inf Dis. 2008;14,(2):260-6.

27. Hosch W, Junghanss T, Werner J, Düx M: Imaging methods in the diagnosis and therapy of cystic echinococcosis. Rofo. 2004;176(5):679-87

28. Mohlitz U, Junghanss T, Razum 0. Zystische Echinokokkose: eine Befragung von Pathologen dient der Surveillance und fürt 74 praktischen Schlussfolgerungen. RKI Epidemiologisches Bulletin 2005;38: 347 - 349, Germany.

29. Grüner B, Kratzer W, Buttenschön K, Kern P, Reuter S. A case of sporadic Echinococcus granulosus infection originary from Southern Germany. Infection. 2008;36(1):78-81.

30. Jorgensen P, an der Heiden M, Kern P, Schöneberg, Krause G, Alpers K. Underreporting of Human Alveolar Echinococcosis, Germany. Emerg Infect Dis. 2008;14 (6):935-7.

This article was published on 4 June 2009.

Citation style for this article: Richter J, Orhun A, Grüner B, Müller-Stöver I, Reuter S, Romig T, Häussinger D, Kern P. Autochthonous cystic echinococcosis in patients who grew up in Germany. Euro Surveill. 2009·14(22):pii=19229. Available online: http://ww eurosurveillance.org/ViewArticle.aspx?ArticleId $=19229$ 


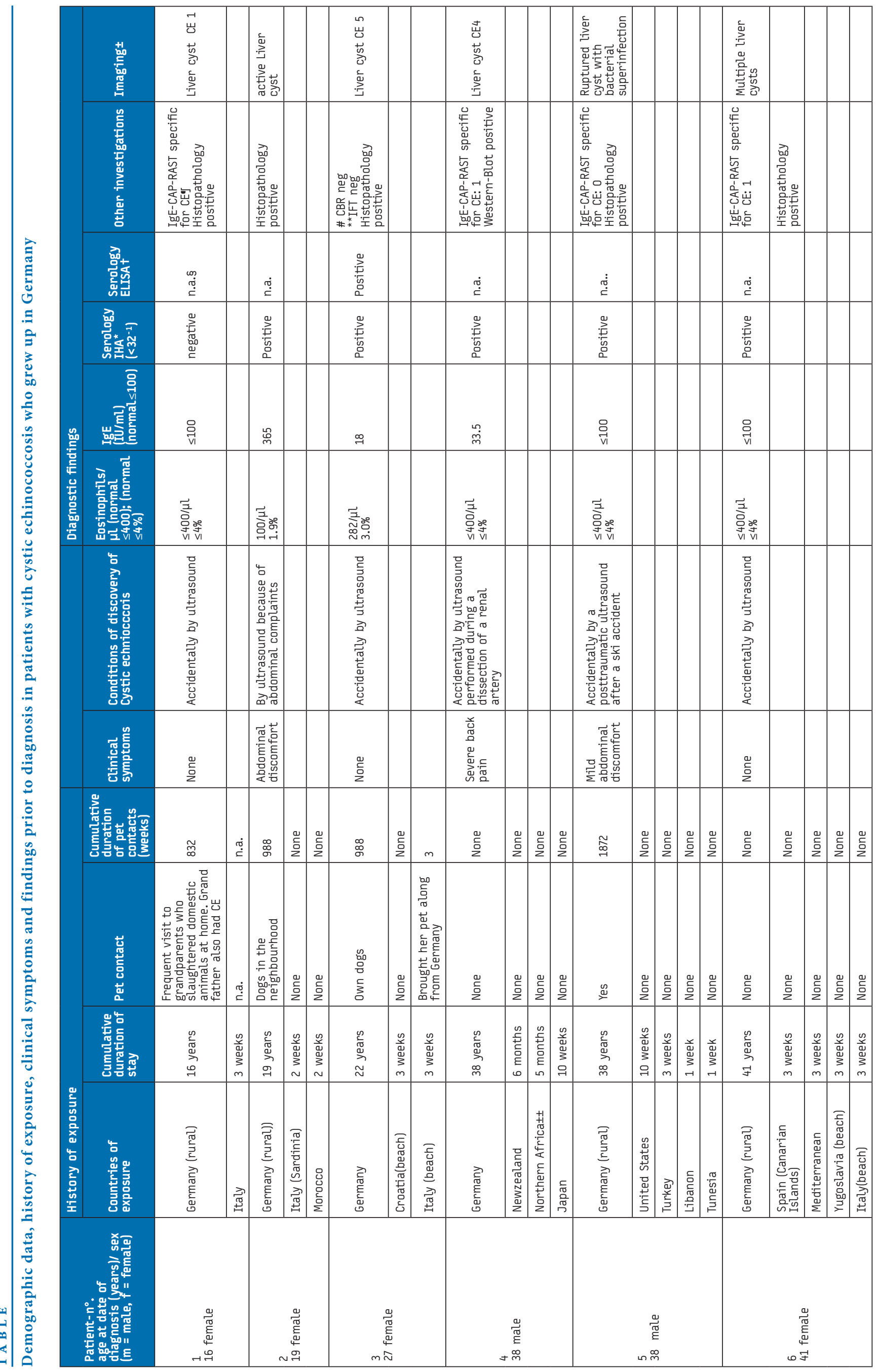




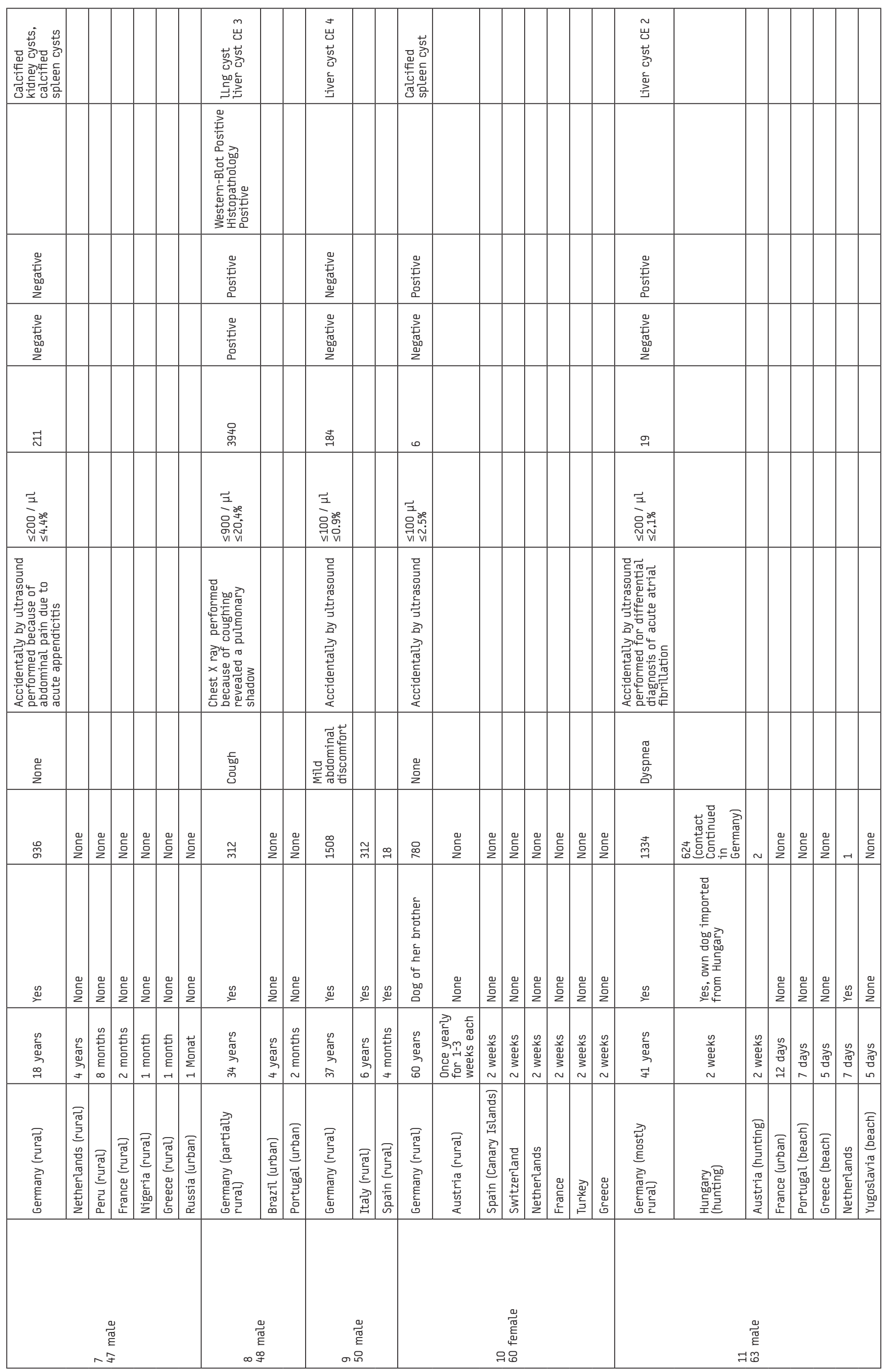




\begin{tabular}{|c|c|c|c|c|c|c|c|c|}
\hline 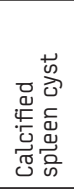 & & & 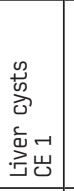 & 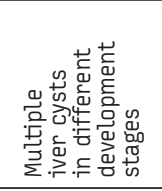 & 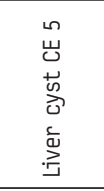 & & & \\
\hline & & & & 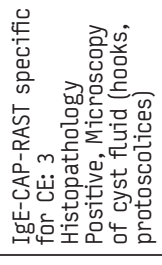 & 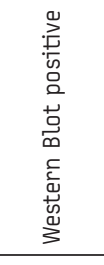 & & & \\
\hline 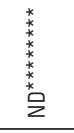 & & & 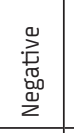 & 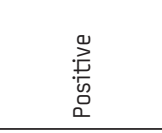 & 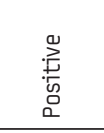 & & & \\
\hline 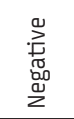 & & & 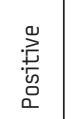 & 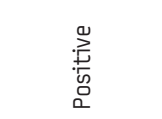 &  & & & \\
\hline$\stackrel{\infty}{m}$ & & & $\stackrel{0}{9}$ & $\stackrel{g}{a}^{m}$ & $\stackrel{్}{g}$ & & & \\
\hline  & & & 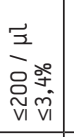 & 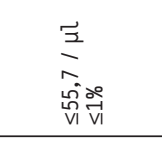 & 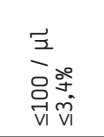 & & & \\
\hline 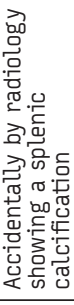 & & & 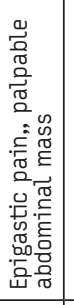 & 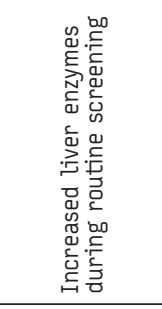 & 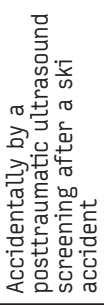 & & & \\
\hline 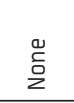 & & & 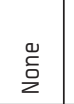 & 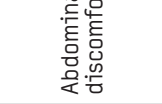 & $\begin{array}{l}\stackrel{0}{\tilde{\Sigma}} \\
\text { L }\end{array}$ & & & \\
\hline$\stackrel{\infty}{\sim}$ & 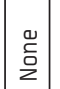 & $\begin{array}{l}\text { 品 } \\
2\end{array}$ & 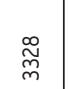 & 志 & 寺 & 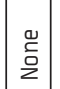 & $\begin{array}{l}\text { 訔 } \\
2\end{array}$ & 䒿 \\
\hline 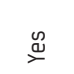 & 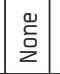 & $\begin{array}{l}0 \\
\vdots \\
\vdots \\
2\end{array}$ & $\stackrel{\infty}{ٍ}$ & $\stackrel{\infty}{\rightleftharpoons}$ & $\stackrel{\varrho}{\check{\varpi}}$ & $\mid \begin{array}{l}0 \\
\tilde{0} \\
2\end{array}$ & $\begin{array}{l}\stackrel{0}{\tilde{\Sigma}} \\
\stackrel{2}{2}\end{array}$ & 䓂 \\
\hline $\begin{array}{l}\stackrel{\infty}{0} \\
\stackrel{0}{\pi} \\
\stackrel{2}{2} \\
\stackrel{0}{0} \\
\end{array}$ & 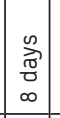 & 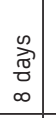 & 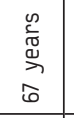 & 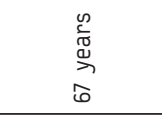 & 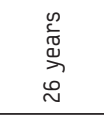 & 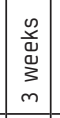 & 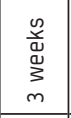 &  \\
\hline 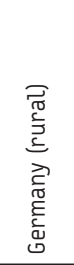 & 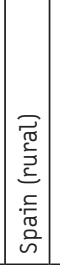 & 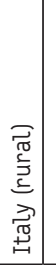 & 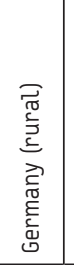 & 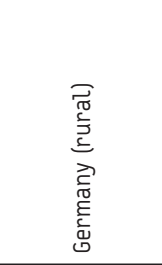 &  & 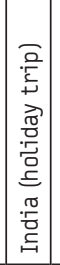 & 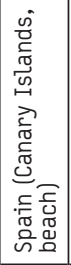 & 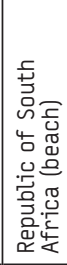 \\
\hline & 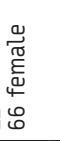 & & 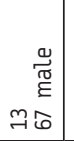 & 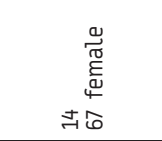 & \multicolumn{4}{|c|}{ 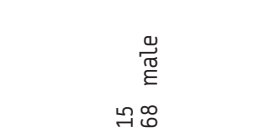 } \\
\hline
\end{tabular}

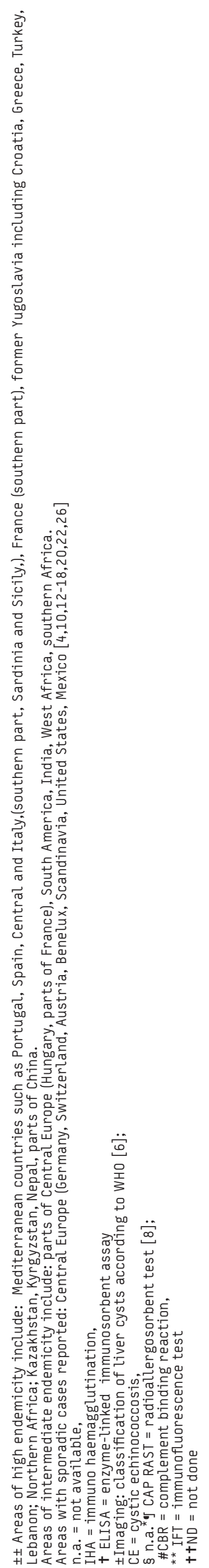

